\title{
COMPLEX SEGREGATION ANALYSIS FOR TWO-LOCUS MODEL: AUTOSOMAL DOUBLE RECESSIVE
}

\author{
Norikazu YASUdA ${ }^{1}$ and Takehiko SASAZUKI ${ }^{2}$ \\ 'Division of Genetics, National Institute of Radiological Sciences, \\ Chiba 260, Japan \\ 2 Department of Human Genetics, Medical Research Institute, \\ Tokyo Medical and Dental University, Tokyo 113, Japan
}

\begin{abstract}
Summary An autosomal doubly recessive mode of inheritance was implemented in segregation analysis, taken into account for segregation frequency, proportion of sporadic cases and ascertainment probability. Maximum likelihood scores are tabulated for some sizes of sibship. Segregation analysis thus becomes much easier with a desk calculator. The procedure has been illustrated for Graves disease.
\end{abstract}

\section{INTRODUCTION}

A search for gene(s) that would express major effect in multifactorial diseases has become widely recognized recently. There is evidence that coeliac disease is the result of two recessive loci (Greenberg and Lange, 1982; Kagnoff, 1982). Hyperlipoproteinemia is the result of two loci (Utermann et al., 1980), Graves disease (Uno et al., 1981) and insulin-dependent diabetes mellitus (Thomson, 1980; Nakao et al., 1981) have both suggested as candidates for a two-locus mode of inheritance. It has also been suggested that other HLA-related diseases, especially autoimmune diseases, may be the result of a locus within the HLA system and a second, nonHLA linked locus (Greenberg and Anderson, 1983).

Segregation analysis has been used to delineate major gene(s) in such diseases (Morton, 1959; 1969) and computer programs have been developed to do necessary calculations which are however so complicated that an access to the procedure was mostly desperate. Therefore, it seems to be desirable to develop simple computational methods with desk calculator.

This statistical method handles data such several families in which each member of a sibship is examined for either healthy or affected status. When the method took into account different segregation frequencies within a given phenotype mating type, it has been called complex segregation analysis (Morton, 1959; 1969; Barrai et al., 1965; Elandt-Johnson, 1970; Lalouel and Morton, 1981).

Received July 18, 1984; revised version received October 30, 1984 
The present paper is concerned with the two-locus models of segregation analysis. The problem however seems not to be so simple. If we consider just two alleles at each of two autosomal loci, nine distinct genotypes be possible, ignoring phase of linkage. The nine genotypes can be deduced to two distinct phenotypes: healthy and affected, by possibly fifty different ways (Hartl and Maruyama, 1968). Defries-Gussenhoven (1962) have studied that five of them deserve special attention, and Elston and Namboodiri (1977) added a sixth to her list.

In this paper we shall study on one of six, doubly autosomal recessive mode of inheritance since the model would encounter very often in practice. Hogben (1932) first studied for statistical test of segregation frequency (p), Li (1953) examined mathematical properties of $\mathrm{p}$, and Elandt-Johnson (1970) has introduced ascertainment probability ( $\pi$ ) to models of complex segregation analysis. She however did not consider one more parameter, proportion of sporadic cases (x). Here, we shall implement all three parameters in complex segregation analysis for the double recessive model. And table will be provided for computation made simple.

\section{MODELS}

Denote two alleles in each locus, $A$ and $a$, and $B$ and $b$. A trait might be an autosomal recessive $a a b b$, and persons who consist of one of the remaining genotypes shall be healthy. Complete penetrance is assumed. When the frequencies of disease gene $a$ and $b$, respectively a and $\mathrm{b}$, were both infrequent or the trait in question is rare, the genotype of healthy couples (abbreviated as $\mathrm{H} \times \mathrm{H}$ ) was likely to be $A a B b \times A a B b$, and those of pairs in which one of parents was affected were likely to be $A a B b \times a a b b$. However if the trait in question is common, more than one segregation frequency can occur within a given parental phenotype mating type. Table 1 shows all genotype mating types, grouped into appropriate segregation frequencies when the ascertainment of families was made through offsprings. The analytic models for segregation distribution could be developed in accordance with the method of ascertainment and parental mating types (Tables 2-4).

Segregation frequency. For phenotype mating type $\mathrm{H} \times \mathbf{H}$, three possible segregations of affected children would be expressed as $1 / 4,1 / 8$ and $1 / 16$ (Table 1) which were implemented in the model as $p_{1}=p, p_{2}=p / 2$ and $p_{3}=p / 4$, where $p$ was a parameter. On the other hand, only the first two $p_{i}$ 's were relevant in $H \times A$ matings. The proportion of mating type for a given segregation frequency could be expressed in terms of the harmonic mean of two normal genes or $\mathrm{k}=2 \mathrm{AB} /(\mathrm{A}+$ $B$ ), where $A=1-a$ and $B=1-b$ (Elandt-Johnson, 1970). Namely, $(1-k)^{2}: 2 k(1-$ $\mathrm{k}): \mathrm{k}^{2}$ for $\mathrm{H} \times \mathrm{H}$ matings, and $1-\mathrm{k}: \mathrm{k}$ for $\mathrm{H} \times \mathrm{A}$ matings (Table 1 ). Then mean segregation frequency will be $(1-k / 2)^{2} / 4$ and $(1-k / 2) / 2$ for $H \times H$ and $H \times A$, respectively. Thus, when $k=0$, either $A$ or $B$ (not both) was absent, the model reduces to the classic segregation model for single recessives (Morton, 1959). Therefore, the parameter $\mathrm{k}$ could be used for testing the null hypothesis of single locus. 
Table 1. Segregation models for doubly autosomal recessive model.

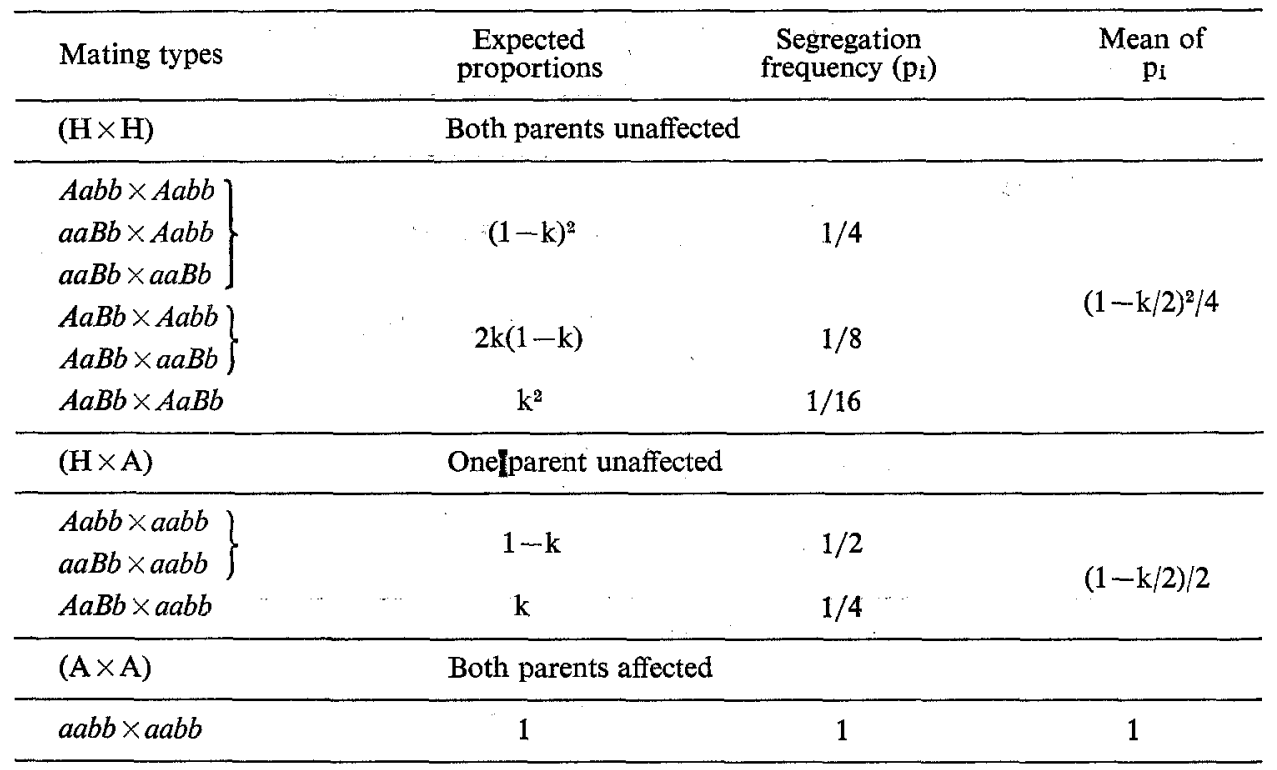

Note: $A$ and $B$ are normal alleles at two loci, respectively, and $a$ and $b$ are recessive genes. For example, the expected proportion of $A a B b \times a a b b$ mating type among $\mathrm{H} \times \mathrm{A}$ phenotype matings $(\mathrm{k})$ can be derived as $8 \mathrm{Aa}^{3} \mathrm{Bb}^{3} /\left(4 \mathrm{Aa}^{3} \mathrm{~b}^{4}+4 \mathrm{a}^{4} \mathrm{Bb}^{3}+8 \mathrm{Aa}^{3} \mathrm{Bb}^{3}\right)=2 \mathrm{AB} /(\mathrm{A}+\mathrm{B})$, in which $\mathrm{A}$ and $\mathrm{B}$ are allelic frequencies of normal genes at two loci, respectively, and $a=1-A$ and $b=1-B$.

Table 2. Expected segregation distribution for doubly autosomal recessive model. Single ascertainment through affected children $(\pi \rightarrow 0)$.

\begin{tabular}{lc}
\hline Matings & Expected probability \\
\hline $\mathrm{H} \times \mathrm{H}$ & $\mathrm{P}(1)=\frac{(1-\mathrm{k})^{2} \mathrm{X}_{1}+\mathrm{k}(1-\mathrm{k}) \mathrm{X}_{2}+(\mathrm{k} / 2)^{2} \mathrm{X}_{3}}{(1-\mathrm{k} / 2)^{2}}$ \\
$\mathrm{H} \times \mathrm{A}(\mathrm{r})=\frac{(1-\mathrm{x})\left[(1-\mathrm{k})^{2} \mathrm{P}_{1}+\mathrm{k}(1-\mathrm{k}) \mathrm{P}_{2}+(\mathrm{k} / 2)^{2} \mathrm{P}_{3}\right]}{(1-\mathrm{k} / 2)^{2}}$ \\
$\mathrm{P}(1)=\frac{(1-\mathrm{k}) \mathrm{X}_{1}+(1-\mathrm{k} / 2) \mathrm{X}_{2}}{1-\mathrm{k} / 2}$ \\
& $\mathrm{P}(\mathrm{r})=\frac{(1-\mathrm{x})\left[(1-\mathrm{k}) \mathrm{P}_{1}+(\mathrm{k} / 2) \mathrm{P}_{2}\right]}{1-\mathrm{k} / 2}$
\end{tabular}

$\mathrm{s}$, sibship size; $r$, number of affected sibs. $\mathrm{p}$ is the parameter for segregation frequency. $\mathrm{x}$ is proportion of sporadic cases. $\mathrm{k}$ is the harmonic mean of two normal genes which determine a conditional mating type frequency (see note of Table 1). $\quad p_{1}=p, p_{2}=p / 2$ and $p_{3}=p / 4 . \quad X_{i}=x+(1-x)\left(1-p_{1}\right)^{s-1} ; P_{1}=\left(\begin{array}{l}\mathfrak{S} \\ )\end{array}\right) p_{i}^{r} \times$ $\left(1-p_{1}\right) s-r$ for $i=1,2,3$. $P(r)$ is the expected segregation distribution for $r=1,2$, $\ldots, s$. In table formulae of $P(r)$ are for $r>1$.

Vol. 29, No. 4, 1984 
Table 3. Expected segregation distribution for doubly autosomal recessive model. Multiple and (truncated) complete ascertainments through children $(0<\pi \leq 1)$.

\begin{tabular}{lc}
\hline Mating types & \multicolumn{1}{c}{ Expected probability } \\
\hline$H \times H$ & $P(1)=\frac{(1-k)^{2} X_{1}+2 k(1-k) X_{2}+k^{2} X_{3}}{(1-k)^{2} Y_{1}+2 k(1-k) Y_{2}+k^{2} Y_{3}}$ \\
& $P(r)=\frac{(1-k)^{2} P_{1}+2 k(1-k) P_{2}+k^{2} P_{3}}{(1-k)^{2} Y_{1}+2 k(1-k) Y_{2}+k^{2} Y_{3}}$ \\
$H \times A$ & $P(1)=\frac{(1-k) X_{1}+k X_{2}}{(1-k) Y_{1}+k Y_{2}}$ \\
& $P(r)=\frac{(1-k) P_{1}+k P_{2}}{(1-k) Y_{1}+k Y_{2}}$
\end{tabular}

$s$, sibship size; $r$, number of affected sibs. $p$ is the parameter for segregation frequency. $x$ is proportion of sporadic cases. $k$ is the harmonic mean of two normal genes which determine a conditional mating type frequency (see note of Table 1). $\mathrm{p}_{1}=\mathrm{p}, \mathrm{p}_{2}=\mathrm{p} / 2$ and $\mathrm{p}_{3}=\mathrm{p} / 4 . \quad \mathrm{X}_{\mathrm{I}}=\mathrm{s} \mathrm{p}_{1} \pi\left[\mathrm{x}+(1-\mathrm{x})\left(1-\mathrm{p}_{1}\right)^{\mathrm{s}-1}\right] ; \mathrm{P}_{\mathrm{i}}=\left(\mathrm{I}_{\mathrm{I}}^{\mathrm{s}}\right) \times$ $\mathrm{p}_{\mathrm{i}} \mathrm{r}\left(1-\mathrm{p}_{1}\right)^{\mathrm{s}-\mathrm{r}} . \quad \mathrm{Y}_{1}=\mathrm{xsp}_{1} \pi+(1-\mathrm{x})\left[1-\left(1-\mathrm{p}_{1 \pi}\right)^{\mathrm{s}}\right]$ for all family, and $\mathrm{Y}_{1}=1-$ $\left(1-p_{i} \pi\right)^{s}-s p_{1} \pi\left(1-p_{i}\right)^{s-1}$ for multiplex family alone. $P(r)$ is the expected segregation distribution for $r=1,2, \ldots, s$. In table formulae of $P(r)$ are for $r>1$.

Table 4. Expected segregation distribution for doubly autosomal recessive model. (Random) complete ascertainment through parent $(\pi=1) *$

\begin{tabular}{ll}
\hline Matings & \multicolumn{1}{c}{ Expected probability } \\
\hline$H \times H$ & $\mathrm{P}(0)=h+(1-h)\left[(1-\mathrm{k})^{2} \mathrm{Q}_{1}+2 \mathrm{k}(1-\mathrm{k}) \mathrm{Q}_{2}+\mathrm{k}^{2} \mathrm{Q}_{3}\right]$ \\
& $\mathrm{P}(\mathrm{r})=(1-\mathrm{h})\left[(1-\mathrm{k})^{2} \mathrm{P}_{1}+2 \mathrm{k}(1-\mathrm{k}) \mathrm{P}_{2}+\mathrm{k}^{2} \mathrm{P}_{3}\right]$ \\
$\mathrm{H} \times \mathrm{A}$ & $\mathrm{P}(0)=\mathrm{h}+(1-\mathrm{h})\left[(1-\mathrm{k}) \mathrm{Q}_{1}+k \mathrm{Q}_{2}\right]$ \\
& $\mathrm{P}(\mathrm{r})=(1-\mathrm{h})\left[(1-\mathrm{k}) \mathrm{P}_{1}+\mathrm{k} \mathrm{P}_{2}\right]$ \\
\hline
\end{tabular}

$s$, sibship size; $r$, number of affected sibs. $p$ is the parameter for segregation frequency. $\mathrm{h}$ is proportion of nonsegregating family. $\mathrm{k}$ is the harmonic mean of two normal genes which determine a conditional mating type frequency (see note of Table 1). $Q_{j}=\left(1-p_{i}\right)^{s} ; P_{i}=\left(\begin{array}{l}s \\ r\end{array}\right) p_{1}{ }^{r}\left(1-p_{i}\right)^{s-r} . P(r)$ is the expected segregation distribution for $r=0,1,2, \ldots, s$. In table formulae of $P(r)$ are for $r>0$. * Tabulation of $P(r)$ and scores and not shown in appendix because of excessive pages and of seldom encountering the case in practice.

Proportion of sporadic cases. When a null hypothesis of $\mathrm{k}=0$ was rejected, it meant simply that data did not fit to a simple single autosomal recessive mode of inheritance. One way to adjust the model to data is to introduce proportion of sporadic cases $(x)$. The concept of sporadics has first introduced in hereditary 
anomalies by Haldane (1949) who distinguished isolated cases from sporadics in simplex families. Occurrences of sporadics in fact suggest nonhomogeneous entities of disease. There are a many mechanisms of sporadics such as mutations, phenocopies, technical errors, extramarital conceptions, rare instances of heterozygous expression of a recessive gene, chromosomal nondisjunction, multifactorial, and possibly environmental. The present model takes into account a portion of sporadics due to double recessives.

Ascertainment probability. This is actually the probability of detecting gene in question in population which happened to multiply in families, and is a nuisance parameter in segregation analysis. Statistically speaking, segregation frequency is rather robust to it while proportion of sporadic cases is somewhat sensitive to it, compared to segregation frequency. Both parameters are almost linearly related with the ascertainment probability $\pi$, but $\mathrm{p}$ is positively one hand and $\mathrm{x}$ is negatively the other hand (Yasuda, 1982). Thus, two extremes of single $(\pi \rightarrow 0)$ and complete $(\pi=1)$ ascertainment were assumed in the analysis in order to assess affects of sampling, provided that no estimate of $\pi$ was available as most usual situations.

\section{STATISTICAL METHODS}

For a given parental phenotype mating type, let $n_{s}$ be the number of families with sibship size $\mathrm{s}$, let $\mathrm{n}_{\mathrm{sr}}$ be the observed number of families of size $\mathrm{s}$ with $\mathrm{r}$ affected sibs, and $P(r)$ be the expected value of $n_{s r}$ or $E\left(n_{s r}\right)=n_{s} P(r)$. Then $u$-scores for respective parameter are defined as the first derivative to the logarithm of likelihood of the observation, while k-scores are obtained from the expectation of product of u-scores; for example,

$$
\mathrm{k}_{\mathrm{pp}}=\mathrm{n}_{\mathrm{s}} \cdot \sum_{\mathrm{r}} \mathrm{u}_{\mathrm{p}}^{2} \mathrm{P}(\mathrm{r}), \quad \mathrm{k}_{\mathrm{px}}=\mathrm{n}_{\mathrm{s}} \cdot \sum_{\mathrm{r}} \mathrm{u}_{\mathrm{p}} \mathrm{u}_{\mathrm{x}} \mathrm{P}(\mathrm{r}), \cdots
$$

The total scores of sample could be calculated additively in terms of sibship size such as $\mathrm{U}_{\mathrm{p}}=\sum_{\mathrm{s}} \mathrm{u}_{\mathrm{p}}$ and $\mathrm{K}_{\mathrm{pp}}=\sum_{\mathrm{s}} \mathrm{k}_{\mathrm{pp}}$.

A test of null hypothesis for a specific parameter may be performed by a statistics $\chi^{2}=\mathrm{U}^{2} / \mathrm{K}$, which asymptotically follows the chi-square distribution with one degree of freedom. Here the subscripts to the scores were omitted for brevity (see, for example Yasuda, 1982).

When a value of $\pi$ was unknown, further modifications of scores could be possible. Having some guess estimates for $\pi$ from experiences in data gathering, the following conventional formulae proved to be practical:

$$
\mathrm{U}=(1-\pi) \mathrm{U}_{0}+\pi \mathrm{U}_{1} \text { and } \mathrm{K}=(1-\pi) \mathrm{K}_{0}+\pi \mathrm{K}_{1}
$$

where the subscript 0 and 1 denote for the value obtained under the assumption of single and complete ascertainment, respectively. By all means, the scores could compute directly for a given value of $\pi$ when a high speed computer was in use. Experience indicates the conventional method be satisfactory. 
In order to make computation simple, numerical values of the probability $\mathrm{P}(\mathrm{r})$ and $\mathrm{u}$-scores for $\mathrm{p}, \mathrm{x}$ and $\mathrm{k}$ are listed in appendix table A1-A4 for some size of sibship.

\section{NUMERICAL EXAMPLE AND DISCUSSION}

Graves disease has been suggested as a candidate for the two-locus mode of inheritance (Uno et al., 1981). In Table 5, segregation distribution were shown for eight nuclear families whose both parents were healthy and for seven families whose one of parents was affected. An attention has been paid for multiplex families in sampling, gathered the nuclear families with at least two affected individuals regardless parent and/or children. In segregation analysis, multiplex family denotes that multiple cases were observed in sibling. Thus, only seven families whose both parents were healthy could be subjected to further analysis. Because of a smallness of sample, the following calculations would rather be for illustration of the method.

Table 6 summarizes the results of computation. Since no distinction of proband and secondary case were informed, computations should be made for two extreme values of $\pi: \pi=0$ and 1 . In the following illustration, the values of $n_{\mathrm{sr}}$ were taken from Table 5 (data), $\mathrm{P}(\mathrm{r})$ and $\mathrm{u}$-scores were from Table A3. For example, the total scores for $\mathrm{U}$ and $\mathrm{K}$ under the null hypothesis of single recessives that $\mathrm{H}_{0}: \mathrm{p}=1 / 4, \mathrm{k}=0, \pi=0$, were calculated as follows:

$$
\begin{aligned}
\mathrm{U}_{\mathrm{p}}= & (2)(-1.5855)+(1)(3.7477)+(1)(-2.4685)+(1)(2.8647) \\
& +(1)(1.9257)=2.8986, \\
\mathrm{U}_{\mathrm{k}}= & (2)(0.1096)+(1)(-0.2792)+(1)(0.1886)+(1)(-0.2650) \\
& +(1)(-0.2416)=-0.3780,
\end{aligned}
$$

Tabie 5. Observed segregation distribution for Graves' disease (Sasazuki, unpublished material).

\begin{tabular}{cccccc}
\hline \multicolumn{3}{c}{ Parental mating: $\mathrm{H} \times \mathrm{H}$} & $: \mathrm{H} \times \mathbf{A}$ \\
\hline $\mathrm{s}$ & $\mathrm{r}=1$ & 2 & 3 & Total & $\mathrm{r}=1$ \\
\hline 1 & 0 & - & - & 0 & 0 \\
2 & 0 & 1 & - & 1 & 1 \\
3 & 0 & 0 & 0 & 0 & 0 \\
4 & 1 & 2 & 1 & 4 & 4 \\
5 & 0 & 1 & 1 & 2 & 2 \\
6 & 0 & 0 & 1 & 1 & 0 \\
\hline Total & 1 & 4 & 3 & 8 & 7
\end{tabular}

s, sibship size; $r$, number of affected sib; $H$, healthy parent; $A$, affected parent. 
Table 6. Complex segregation analysis of Graves disease with multiplex families alone.

\begin{tabular}{|c|c|c|c|c|c|c|c|c|c|c|}
\hline \multicolumn{4}{|c|}{ Null hypothesis tested } & \multicolumn{6}{|c|}{$\mathrm{H}_{0}: \mathrm{p}=1 / 4, \mathrm{k}=0$ and $\pi \rightarrow 0$} & \multirow[b]{2}{*}{$\mathrm{k}_{\mathrm{kk}}$} \\
\hline $\mathrm{s}$ & $\mathrm{r}$ & $\mathrm{n}_{\mathrm{sr}}$ & $\left(\mathrm{n}_{\mathrm{s}}\right)$ & $\exp$ & $\mathrm{P}(\mathrm{r})$ & $u_{p}$ & $\mathbf{u}_{\mathbf{x}}$ & $\mathrm{k}_{\mathrm{pp}}$ & $k_{p k}$ & \\
\hline 2 & 2 & 1 & (1) & 1.00 & 1.0000 & - & - & - & - & - \\
\hline 4 & 2 & 2 & (3) & 2. 19 & 0.7297 & -1.59 & 0.11 & 5.50 & -0.38 & 0.03 \\
\hline 4 & 3 & 1 & (3) & 0.73 & 0.2432 & 3.75 & -0.28 & 10.25 & -0.76 & 0.06 \\
\hline 4 & 4 & 0 & (3) & 0.08 & 0.0271 & $*$ & $*$ & $*$ & $*$ & $*$ \\
\hline 5 & 2 & 1 & (2) & 1.23 & 0.6171 & -2.47 & 0.19 & 7.52 & -0.57 & 0.04 \\
\hline 5 & 3 & 1 & (2) & 0.62 & 0.3085 & 2. 86 & -0.27 & 5.06 & -0.47 & 0.04 \\
\hline 5 & $4 \leq$ & 0 & (2) & 0.15 & 0.0744 & $*$ & $*$ & $*$ & $*$ & $*$ \\
\hline 6 & 2 & 0 & (1) & 0.52 & 0.5185 & * & * & * & * & * \\
\hline 6 & 3 & 1 & (1) & 0.35 & 0,3457 & 1.93 & -0.24 & 1. 28 & -0.16 & 0.02 \\
\hline 6 & $4 \leq$ & 0 & (1) & 0.14 & 0.1358 & $*$ & $*$ & $*$ & $*$ & $*$ \\
\hline \multicolumn{2}{|l|}{ Total } & 7 & & & & 2.90 & -0.38 & 29.62 & -2.35 & 0.19 \\
\hline \multicolumn{4}{|c|}{$\mathrm{U}^{2} / \mathrm{K}(\mathrm{df}=1)$} & & & 0.28 & 0.75 & & & \\
\hline$x^{2}$ & $(\mathrm{df}=$ & & & 2.52 & & & & & & \\
\hline \multicolumn{5}{|c|}{ Null hypothesis tested } & \multicolumn{4}{|c|}{$\mathrm{H}_{0}: \mathrm{p}=1 / 4, \mathrm{k}=0$ and $\pi=1$} & & \\
\hline $\mathrm{s}$ & $\mathrm{r}$ & $\mathrm{n}_{\mathrm{sr}}$ & $\left(\mathrm{n}_{\mathrm{s}}\right)$ & $\exp$ & $P(r)$ & $\mathrm{u}_{\mathrm{p}}$ & $\mathrm{u}_{\mathrm{k}}$ & $\mathrm{k}_{\mathrm{pp}}$ & $\mathrm{k}_{\mathrm{pk}}$ & $\mathbf{k}_{\mathrm{kk}}$ \\
\hline 2 & 2 & 1 & (1) & 1.00 & 1.0000 & - & - & - & - & 一 \\
\hline 4 & 2 & 2 & (3) & 2.42 & 0.8059 & -1.11 & 0.08 & 3.00 & -0.21 & 0.01 \\
\hline 4 & 3 & 1 & (3) & 0.54 & 0.1791 & 4.21 & -0.31 & 9.56 & -0.70 & 0.05 \\
\hline 4 & 4 & 0 & (3) & 0.04 & 0.0149 & $*$ & * & $*$ & * & $*$ \\
\hline 5 & 2 & 1 & (2) & 1.44 & 0.7180 & -1.74 & 0.14 & 4. 37 & -0.34 & 0.03 \\
\hline 5 & 3 & 1 & (2) & 0.48 & 0.2393 & $3.59^{\circ}$ & -0.32 & 6.16 & -0.54 & 0.05 \\
\hline 5 & $4 \leq$ & 0 & (2) & 0.08 & 0.0427 & $*$ & $*$ & $*$ & * & $*$ \\
\hline 6 & 2 & 0 & (1) & 0.64 & 0.6364 & $*$ & $*$ & * & $*$ & $*$ \\
\hline 6 & 3 & 1 & (1) & 0.28 & 0.2828 & 2.91 & -0.32 & 2.39 & -0.26 & 0.03 \\
\hline 6 & $4 \leq$ & 0 & (1) & 0.08 & 0.0808 & * & $*$ & $*$ & $*$ & $*$ \\
\hline \multicolumn{2}{|l|}{ Total } & 7 & & & & 6.74 & -0.65 & 25.49 & -2.06 & 0.17 \\
\hline \multicolumn{4}{|c|}{$\mathrm{U}^{2} / \mathrm{K}(\mathrm{df}=1)$} & & & 1.78 & 2.51 & & & \\
\hline$\chi^{2}$ & $(\mathrm{df}=$ & & & 3.84 & & & & & & \\
\hline
\end{tabular}

$s$, sibship size; $r$, number of affected sib; $n_{s r}$, number of family with $s$ and $r ; n_{s}$, number of family with sibship size s. * Score was not shown here since it was unnecessary in computation when $n_{s r}=$ 0 . 


$$
\begin{aligned}
\mathrm{K}_{\mathrm{pp}}= & (3)(0.7297)(-1.5855)^{2}+(3)(0.2432)(3.7477)^{2} \\
& +(2)(0.6171)(-2.4685)^{2}+(2)(0.3085)(2.8647)^{2} \\
& +(1)(0.3457)(1.9257)^{2}=29.6164 \\
\mathrm{~K}_{\mathrm{pk}}= & (3)(0.7297)(-1.5855)(0.1096)+(3)(0.2432)(3.7477) \\
& (-0.2792)+(2)(0.6171)(-2.4685)(0.1886)+(2)(0.3085) \\
& (2.8647)(-0.2650)+(1)(0.3457)(1.9257)(-0.2416) \\
& =-2.3476, \text { and } \\
\mathrm{K}_{\mathrm{kk}}= & (3)(0.7297)(0.1096)^{2}+(3)(0.2432)(-0.2792)^{2} \\
& +(2)(0.6171)(0.1886)^{2}+(2)(0.3085)(-0.2650)^{2} \\
& +(1)(0.3457)(-0.2416)^{2}=0.1906 .
\end{aligned}
$$

The corresponding scores under the other null hypothesis that $\mathrm{H}_{0}: p=1 / 4, k=0$ and $\pi=1$ were

$$
\begin{aligned}
& \mathrm{U}_{\mathrm{p}}=6.7424 \text { and } \mathrm{U}_{\mathrm{k}}=-0.6536, \text { and } \\
& \mathrm{K}_{\mathrm{pp}}=25.4920, \mathrm{~K}_{\mathrm{pk}}=-2.0625 \text { and } \mathrm{K}_{\mathrm{kk}}=0.1700
\end{aligned}
$$

respectively. Here $P(r)$ and $u$-scores were from Table A3. No statistical significances at five percent level were observed under both null hypotheses. Namely, the values of chisquare for segregation frequency were $(2.8986)^{2} / 29.6164=0.28$ and $(6.7424)^{2} / 25.4920=1.78$ under the assumption of single and complete ascertainment, respectively. Since the chisquare values for single locus hypothesis $(k=0)$ were $(-0.3780)^{2} / 0.1906=0.75$ and $(-0.6536)^{2} / 0.1700=2.51$ for single and complete ascertainment, respectively, a single autosomal recessive mode of inheritance could not be rejected in the present material.

However, evidences have been shown for HLA-linked and Gm-linked genes in Graves disease (Uno et al., 1981; Sasazuki et al., 1982). Two genetic models have been proposed in Graves disease by the affected sibpair method (Yasuda and Sasazuki, 1982): (i) an HLA-linked recessive gene with frequency 0.30 and a Gm-linked recessive gene with frequency 0.10 ; and (ii) an HLA-linked dominant gene with frequency 0.08 and a $\mathrm{Gm}$-linked recessive gene with frequency 0.10 . It is therefore of most interest to examine whether doubly recessive hypothesis that $\mathrm{H}_{0}: \mathrm{p}=1 / 16$, $\mathrm{k}=2 \times 0.7 \times 0.9 /(0.7+0.9)=0.7875$ and $\pi=0$ or 1 fit to the data. The results of segregation analysis by a high speed computer were summarized in Table 7 . Fits were very good. It can also be shown that the data fitted well with the other two locus model.

Although no statistical distinction between one and/or two locus mode of inheritance could be made in this particular example of Graves disease by segregation analysis, probably because of a smallness of sample size, a joint approach of affected sibpair method and segregation analysis should be promising. For instance, affected sibpair method would provide frequency of disease gene for complex segregation analysis.

Greenberg (1984) has examined the power of segregation analysis to distinguish 
between one- and two-locus models for recessive mode of inheritance. Among other things, he did extensive computer simulations and found that the method has a sufficient power to distinguish between the fully penetrant single and doubly recessive models. He has also found that the method could also distinguish fairly well between the dominant-recessive and single recessive hypotheses. We have been developing a computer program implemented six genetic hypotheses mentioned previously, and will communicate it elsewhere.

Table 7. Tests of fit for doubly autosomal recessives to multiplex families of Graves disease.

\begin{tabular}{|c|c|c|c|c|c|c|c|c|c|}
\hline \multicolumn{5}{|c|}{ Single ascertainment $(\pi \rightarrow 0)$} & \multicolumn{5}{|c|}{ Complete ascertainment $(\pi=1)$} \\
\hline $\begin{array}{l}\text { Parameter } \\
\text { tested }\end{array}$ & $\mathbf{U}$ & $\mathbf{K}$ & $\begin{array}{c}\mathrm{U}^{2} / \mathrm{K} \\
(\mathrm{df}=1)\end{array}$ & $\left(\begin{array}{l}\chi^{2} \\
(\mathrm{df})\end{array}\right.$ & $\begin{array}{l}\text { Parameter } \\
\text { tested }\end{array}$ & $\mathbf{U}$ & $\mathbf{K}$ & $\begin{array}{c}\mathrm{U}^{2} / \mathbf{K} \\
(\mathrm{df}=1)\end{array}$ & $\begin{array}{c}\chi^{2} \\
(\mathrm{df})\end{array}$ \\
\hline $\mathrm{p}=1 / 16$ & 17.65 & 740.45 & 0.42 & $3.26(5)$ & $\mathrm{p}=1 / 16$ & 29.80 & 533.10 & 1.67 & $5.14(5)$ \\
\hline$k=0.7875$ & -0.94 & 1.01 & 0.87 & & $\mathrm{k}=0.7875$ & -1.40 & 0.78 & 2.50 & \\
\hline $\begin{aligned} \hat{\mathrm{p}}= & 0.0839 \\
& \pm 0.0391\end{aligned}$ & -0.00 & 653.95 & 0.00 & $2.53(4)$ & $\begin{aligned} \hat{\mathrm{p}}= & 0.1067 \\
& \pm 0.0461\end{aligned}$ & 0.00 & 470.65 & 0.00 & $2.90(4)$ \\
\hline$k=0.7875$ & -0.42 & 1.72 & 0.10 & & $\mathrm{k}=0.7875$ & -0.61 & 2.47 & 0.15 & \\
\hline
\end{tabular}

$\overline{\mathrm{U}}$ and $\mathrm{K}$ are scores for the corresponding parameter. $\mathrm{U}^{2} / \mathrm{K}$ is a value of chisquare for testing a given value of the paramter. $\chi^{2}$ for a goodness of fit of segregation distribution to the expectation. $\hat{p}$ is the estimated segregation frequency under a constraint $\mathrm{k}=0.7875$.

Table 8. A goodness of fit to doubly autosomal recessive model with two recessive gene frequencies 0.30 and 0.10 in Graves disease.

\begin{tabular}{ccccc}
\hline$s$ & $\mathrm{r}$ & obs & $\begin{array}{c}\text { Expectation under } \mathrm{H}_{0}: \mathrm{p}=1 / 16, \\
\mathrm{k}=0.7875 \mathrm{and} \\
\pi=1\end{array}$ \\
\hline 2 & 2 & 1 & 1.00 & 1.00 \\
4 & 2 & 2 & 2.31 & 2.51 \\
4 & 3 & 1 & 0.62 & 0.45 \\
4 & 4 & 0 & 0.06 & 0.03 \\
5 & 2 & 1 & 1.35 & 1.53 \\
5 & 3 & 1 & 0.53 & 0.40 \\
5 & 4,5 & 0 & 0.12 & 0.06 \\
6 & 2 & 0 & 0.59 & 0.70 \\
6 & 3 & 1 & 0.30 & 0.24 \\
6 & $4,5,6$ & 0 & 0.10 & 0.06 \\
\hline Total & & 7 & 7.00 & 7.00 \\
\hline$\chi^{2}(\mathrm{df}=5)$ & & 3.26 & 5.14 \\
\hline $\mathrm{k}=2 \times 0.7 \times 0.9 /(0.7+0.9)=0.7875$. & & \\
\hline
\end{tabular}

Vol. 29, No. 4, 1984 
Table A1. Probability and $u$ scores for the hypothesis that $H_{0}: p=1 / 4, x=0, k=0$ and $\pi$ in the doubly recessive model. I. Simplex and multiplex families.

\begin{tabular}{|c|c|c|c|c|c|c|c|c|c|c|c|}
\hline \multirow[b]{2}{*}{ s } & \multirow[b]{2}{*}{$\mathbf{r}$} & \multicolumn{4}{|c|}{ Single ascertainment $(\pi \rightarrow 0)$} & \multicolumn{4}{|c|}{ Truncated ascertainment $(\pi=1)$} & \multirow[b]{2}{*}{ s } & \multirow[b]{2}{*}{ 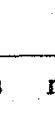 } \\
\hline & & $\mathrm{P}(\mathrm{r})$ & $\mathrm{u}_{\mathrm{p}}$ & $u_{x}$ & uk & $\mathrm{P}(\mathrm{r})$ & $\mathrm{u}_{\mathrm{p}}$ & $u_{x}$ & $\mathrm{u}_{\mathrm{K}}$ & & \\
\hline 2 & 1 & 0.7500 & 1.3333 & 0.3333 & 1666 & 0.8571 & -0.7619 & 0.1904 & 0.0952 & 2 & 1 \\
\hline 2 & 2 & 00 & 4.0000 & -1 & 0 & 28 & 14 & -1.1428 & 14 & & 2 \\
\hline 3 & 1 & 0.5625 & -2.6666 & 0.7777 & 0.3611 & 0.7297 & -1.5855 & 0.4804 & 0.2192 & 3 & 1 \\
\hline 3 & 2 & 0.3750 & 2.6666 & -1 & -0.4166 & 0.2432 & 3.7477 & -1.2973 & -0.5585 & 3 & 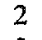 \\
\hline 3 & 3 & 0.0625 & 8.0000 & -1 & 500 & 0.0270 & 9.0810 & -1.2973 & -0.8918 & & 3 \\
\hline 4 & $1^{-}$ & 0.4218 & -4.0000 & 1.3703 & 0.5879 & 0.6171 & -2.4685 & 0.9075 & 0.3772 & 4 & 1 \\
\hline 4 & 2 & 0.4218 & 1.3333 & -1 & $-0,3194$ & 0.3085 & 2.8647 & -1.4628 & -0.5301 & 4 & 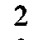 \\
\hline 4 & 3 & 0.1406 & 6.6666 & -1 & -0.7083 & 0.0685 & 8.1981 & -1.4628 & -0.9190 & & 3 \\
\hline & 4 & 0.0156 & 12.0000 & -1 & -0.8750 & 0.0057 & 13.5314 & -1.4628 & -1.0857 & 4 & 4 \\
\hline 5 & 1 & 0.3164 & -5.3333 & 2.1604 & 0.8526 & 0.5185 & -3.4076 & 1.5215 & 0.5753 & 5 & 1 \\
\hline 5 & 2 & 0.4218 & 0.0000 & -1 & -0.2060 & 0.3 & 57 & -1.6389 & -0 & 5 & 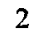 \\
\hline 5 & 3 & 0.2109 & 5.3333 & -1 & -0.6597 & 0.1152 & 7.2590 & -1.6389 & -0.9370 & 5 & 3 \\
\hline 5 & 4 & 0.0468 & 10.6666 & -1 & -0.8541 & 0.0192 & 12.5924 & -1.6389 & -1.1314 & 5 & 4 \\
\hline & 5 & 0.0039 & 16.0000 & -1 & -0.9375 & 0.0012 & 17.9257 & -1.6389 & -1.2147 & 5 & 5 \\
\hline & 1 & 2373 & 5.6666 & 3.2 & 1.1613 & 4330 & -4 & 2. 3892 & 0.8203 & 6 & 1 \\
\hline 6 & 2 & 955 & 3 & -1 & -0.0736 & & 0. & -1 & -0 & 6 & 2 \\
\hline 6 & 3 & 0.2636 & 4.0000 & -1 & -0.6030 & 0.1 & 6.2 & -1.8247 & -0.9441 & 6 & 3 \\
\hline 6 & 4 & 0.0878 & 9.3333 & -1 & -0.8298 & 0.0401 & 11.6012 & -1.8247 & -1.1709 & 6 & 4 \\
\hline 6 & 5 & 0.0146 & 14.6666 & -1 & -0.9270 & 0.0053 & 16.9345 & -1.8247 & -1.2681 & 6 & 5 \\
\hline 6 & 6 & 0.0009 & 20.0000 & -1 & -0.9687 & 0.0003 & 22.2678 & -1.8247 & -1.3098 & 6 & 0 \\
\hline & 1 & 0.1779 & 00 & 4. 61 & 1.9216 & 0.3594 & -5.4 & 3. 5990 & 99 & 7 & 1 \\
\hline 7 & 2 & 0 & 6 & -1 & 77 & & -0 & -2 & -0 & 7 & 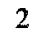 \\
\hline 7 & 3 & 0.2966 & 2.6666 & -1 & -0.5368 & 0.1996 & 5.2289 & -2.0195 & -0.9385 & 7 & 3 \\
\hline 7 & 4 & 0.1318 & 8.0000 & -1 & -0.8015 & 0. & & -2.0 & -1 & 7 & 1 \\
\hline 7 & 5 & 0.0329 & 13.3 & -1 & -0.9149 & 0.0 & 15.8955 & -2.0195 & -1.3166 & 7 & 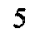 \\
\hline 7 & 6 & 0.0043 & 18.6666 & -1 & -0.9635 & 0.0 & 21.2289 & -2.0195 & -1.3652 & 7 & 6 \\
\hline 7 & 7 & 0.0002 & 24,0000 & -1 & -0.9843 & 0.0000 & 26.5622 & -2.0195 & -1.3860 & 7 & 7 \\
\hline 8 & 1 & 0.1334 & -9.3333 & 6.4 & 1.9419 & 0.2966 & -6 & 5.2690 & 30 & 8 & 1 \\
\hline 8 & 2 & 0.3114 & -4.0000 & -1 . & 0.2608 & 0.3461 & -1.1866 & -2.2225 & -0.1980 & 8 & 2 \\
\hline & 3 & 0.3114 & 1.3333 & -1 & -0.4596 & 0.2307 & 4.1466 & -2.2225 & -0.9184 & 8 & 3 \\
\hline 8 & 4 & 0.1730 & 6.6666 & -1 & -0.7684 & 0.0961 & 9.4799 & -2.2225 & -1.2272 & 8 & 4 \\
\hline 8 & 5 & 0.0576 & 12.0000 & -1 & -0.9007 & & & -2.2225 & -1.3595 & & 5 \\
\hline & 6 & 0.0115 & 17.3333 & -1 & -0.9574 & 0.0042 & 20.1466 & -2.2225 & -1.4163 & 8 & 0 \\
\hline 8 & 7 & 0.0012 & 22.6666 & -1 & -0.9817 & 0.0004 & 25.4799 & -2.2225 & -1.4406 & 8 & 7 \\
\hline 8 & 8 & 0.0000 & 28.0000 & -1 & -0.9921 & 0.0000 & 30.8133 & -2.2225 & -1.4510 & 8 & 8 \\
\hline 9 & 1 & 0.1001 & -10.6666 & 8.9 & 2.4322 & 0.2435 & -7.6408 & 7.5560 & 1.9199 & 9 & 1 \\
\hline 9 & 2 & 0.2669 & -5.3333 & -1 & 0.4709 & 47 & -2.3074 & -2.4326 & -0.0412 & 9 & 2 \\
\hline 9 & 3 & 0.3114 & 0.0000 & -1 & -0.3695 & 0.2525 & 3.0258 & -2.4326 & -0.8818 & 9 & 3 \\
\hline 9 & 4 & 0.2076 & 5.3333 & -1 & -0.7298 & 0.1262 & 8.3591 & -2.4326 & -1.2420 & 9 & 4 \\
\hline 9 & 5 & 0.0865 & 10.6666 & -1 & -0.8842 & 0.0420 & 13.6925 & -2.4326 & -1.3964 & 9 & 5 \\
\hline 9 & 6 & 0.0230 & 16.0000 & -1 & -0.9503 & 0.0093 & 19.0258 & -2.4326 & -1.4626 & 9 & 6 \\
\hline 9 & 7 & 0.0038 & 21.3333 & -1 & -0.9787 & 0.0013 & 24.3591 & -2.4326 & -1.4909 & 9 & 7 \\
\hline 9 & 8 & 0.0003 & 26.6666 & -1 & -0.9908 & 0.0001 & 29.6925 & -2.4326 & -1.5031 & 9 & 8 \\
\hline 9 & 2 & 0.0000 & 32.0000 & -1 & -0.9960 & 0.0000 & 35.0258 & -2.4326 & -1.5083 & 9 & 0 \\
\hline
\end{tabular}

Note: Omitted the figure below the fifth place of decimals. 
Table A2. Probability and $u$ scores for the hypothesis that $H_{0}: p=1 / 2, x=0, k=0$ and $\pi$ in the doubly recessive model. I. Simplex and multiplex families.

\begin{tabular}{|c|c|c|c|c|c|c|c|c|c|c|c|}
\hline \multirow[b]{2}{*}{$s$} & \multirow[b]{2}{*}{$\mathrm{r}$} & \multicolumn{4}{|c|}{ Single ascertainment $(\pi \rightarrow 0)$} & \multicolumn{4}{|c|}{ Truncated ascertainment $(\pi=1)$} & \multirow[b]{2}{*}{$\mathbf{S}$} & \multirow[b]{2}{*}{$\mathrm{r}$} \\
\hline & & $P(r)$ & $\mathfrak{u}_{\mathrm{p}}$ & $\mathrm{u}_{\mathbf{x}}$. & $u_{\mathrm{k}}$ & $\mathrm{P}(\mathrm{r})$ & $u_{p}$ & $\mathrm{u}_{\mathrm{x}}$ & $\mathbf{u}_{\mathrm{k}}$ & & \\
\hline 2 & 1 & 0.5000 & -2 & 1. & 0.2500 & 0.6666 & -1.3333 & 0.6666 & 0.1616 & 2 & 1 \\
\hline 2 & 2 & 0.5000 & 2. & -1 & -0.2500 & 0.3333 & 2.6666 & -1.3333 & -0.3333 & 2 & 2 \\
\hline 3 & 1 & 0.2500 & -4 & 3. & 0.6250 & 0.4285 & -2.8571 & 2.2857 & 0.4642 & 3 & 1 \\
\hline 3 & 2 & 0.5000 & 0 & -1 & -0.1250 & 0.4285 & 1.1428 & -1.7142 & -0.2857 & 3 & 2 \\
\hline 3 & 3 & 0.2500 & 4. & -1 & -0.3750 & 0.1428 & 5.1428 & -1.7142 & -0.5357 & 3 & 3 \\
\hline 4 & 1 & 0.1250 & -6 & 7. & 1.1875 & 0.2666 & -4.5333 & 5.8666 & 0.9583 & 4 & 1 \\
\hline 4 & 2 & 0.3750 & -2 & -1 & 0.0625 & 0.4000 & -0.5333 & -2.1333 & -0.1666 & 4 & 2 \\
\hline 4 & 3 & 0.3750 & & -1 & -0.3125 & 0.2666 & 3. 4666 & -2.1333 & -0.5416 & 4 & 3 \\
\hline 4 & 4 & 0.1250 & & -1 & -0.4375 & 0.0666 & 7.4666 & -2.1333 & -0.6666 & 4 & 4 \\
\hline 5 & 1 & 0.0625 & -8 & 15. & 2.0312 & 0.1612 & -6.3225 & 13.4193 & 1.7439 & 5 & 1 \\
\hline 5 & 2 & 0.2500 & -4 & -1 & 0.3437 & 0.3225 & -2.3225 & -2.5806 & 0.0564 & 5 & 2 \\
\hline 5 & 3 & 0.3750 & 0. & -1 & -0.2187 & 0.3225 & 1. 6774 & -2.5806 & -0.5060 & 5 & 3 \\
\hline 5 & 4 & 0.2500 & 4. & -1 & -0.4062 & 0.1612 & 5.6774 & -2.5806 & -0.6935 & 5 & 4 \\
\hline 5 & 5 & 0.0625 & 8. & -1 & -0.4687 & 0.0322 & 9.6774 & -2.5806 & -0.7560 & 5 & 5 \\
\hline 6 & 1 & 0.0312 & -10 & 31. & 3. 2968 & 0.0952 & -8.1904 & 28.9523 & 2.9618 & 6 & 1 \\
\hline 6 & 2 & 0.1562 & -6 & -1 & 0.7656 & 0.2381 & -4.1904 & -3.0476 & 0.4305 & 6 & 2 \\
\hline 6 & 3 & 0.3125 & -2 & -1 & -0.0781 & 0.3174 & -0.1904 & -3.0476 & -0.4131 & 6 & 3 \\
\hline 6 & 4 & 0.3125 & 2. & -1 & -0.3593 & 0.2381 & 3.8095 & -3.0476 & -0.6944 & 6 & 4 \\
\hline 6 & 5 & 0.1562 & 6. & -1 & -0.4531 & 0.0952 & 7.8095 & -3.0476 & -0.7881 & 6 & 5 \\
\hline 6 & 6 & 0.0312 & 10. & -1 & -0.4843 & 0.0158 & 11.8095 & -3.0476 & -0.8194 & 6 & 6 \\
\hline 7 & 1 & 0.0156 & -12 & 63. & 5. 1953 & 0.0551 & -10.1102 & 60.4724 & 4. 8219 & 7 & 1 \\
\hline 7 & 2 & 0.0937 & -8 & -1 & 1. 3984 & 0.1653 & -6.1102 & -3.5275 & 1.0251 & 7 & 2 \\
\hline 7 & 3 & 0.2343 & -4 & -1 & 0.1328 & 0.2755 & -2.1102 & -3.5275 & -0.2405 & 7 & 3 \\
\hline 7 & 4 & 0.3125 & 0. & -1 & -0.2890 & 0.2755 & 1.8897 & -3.5275 & -0.6624 & 7 & 4 \\
\hline 7 & 5 & 0.2343 & 4. & -1 & -0.4296 & 0.1653 & 5.8897 & -3.5275 & -0.8030 & 7 & 5 \\
\hline 7 & 6 & 0.0937 & 8. & -1 & -0.4765 & 0.0551 & 9.8897 & -3.5275 & -0.8499 & 7 & 6 \\
\hline 7 & 7 & 0.0156 & 12. & -1 & -0.4921 & 0.0078 & 13.8897 & -3.5275 & -0.8655 & 7 & 7 \\
\hline 8 & 1 & 0.0078 & -14 & 127. & 8.0429 & 0.0313 & -12.0627 & 123.9843 & 7.6395 & 8 & 1 \\
\hline 8 & 2 & 0.0546 & -10 & -1 & 2. 3476 & 0.1098 & -8.0627 & -4.0156 & 1.9442 & 8 & 2 \\
\hline 8 & 3 & 0.1640 & -6 & -1 & 0.4492 & 0.2196 & -4.0627 & -4.0156 & 0.0458 & 8 & 3 \\
\hline 8 & 4 & 0.2734 & -2 & -1 & -0.1835 & 0.2745 & -0.0627 & -4.0156 & -0.5870 & 8 & 4 \\
\hline 8 & 5 & 0.2734 & 2. & -1 & -0.3945 & 0.2196 & 3.9372 & -4.0156 & -0.7979 & 8 & 5 \\
\hline 8 & 6 & 0.1640 & 6. & -1 & -0.4648 & 0.1098 & 7.9372 & -4.0156 & -0.8682 & 8 & 6 \\
\hline 8 & 7 & 0.0546 & 10. & -1 & -0.4882 & 0.0313 & 11.9372 & -4.0156 & -0.8917 & 8 & 7 \\
\hline 8 & 8 & 0.0078 & 14. & -1 & -0.4960 & 0.0039 & 15.9372 & -4.0156 & -0.8995 & 8 & 8 \\
\hline 9 & 1 & 0.0039 & -16 & 255 & 12.3144 & 0.0176 & -14.0352 & 251.4911 & 11.8877 & 9 & 1 \\
\hline 9 & 2 & 0.0312 & -12 & -1 & 3. 7714 & 0.0704 & -10.0532 & -4.5088 & 3. 3447 & 9 & 2 \\
\hline 9 & 3 & 0.1093 & -8 & -1 & 0.9238 & 0.1643 & -6.0352 & -4.5088 & 0.4971 & 9 & 3 \\
\hline 9 & 4 & 0.2187 & -4 & -1 & -0.0253 & 0.2465 & -2.0352 & -4.5088 & -0.4521 & 9 & 4 \\
\hline 9 & 5 & 0.2734 & 0. & -1 & -0.3418 & 0.2465 & 1.9647 & -4.5088 & -0.7685 & 9 & 5 \\
\hline 9 & 6 & 0.2187 & 4. & -1 & -0.4472 & 0.1643 & 5.9647 & -4.5088 & -0.8739 & 9 & 6 \\
\hline 9 & 7 & 0.1093 & 8. & -1 & -0.4824 & 0.0704 & 9.9647 & -4.5088 & -0.9091 & 9 & 7 \\
\hline 9 & 8 & 0.0312 & 12. & -1 & -0.4941 & 0.0176 & 13.9647 & -4.5088 & -0.9208 & 9 & 8 \\
\hline 9 & 9 & 0.0039 & 16. & -1 & -0.4980 & 0.0019 & 17.9647 & -4.5088 & -0.9247 & 9 & 9 \\
\hline
\end{tabular}

Note: Omitted the figure below the fifth place of decimals. 
Table A3. Probability and $\mathrm{u}$ scores for hypothesis that $\mathrm{H}_{0}: \mathrm{p}=1 / 4, \mathrm{k}=0$ and $\pi$ in the doubly recessive model. II. Multiplex family alone.

\begin{tabular}{|c|c|c|c|c|c|c|c|c|c|}
\hline \multicolumn{5}{|c|}{ Single ascertainment $(\pi \rightarrow 0)$} & \multicolumn{5}{|c|}{ Truncated ascertainment $(\pi=1)$} \\
\hline $\mathrm{s}$ & $r$ & $\mathrm{P}(\mathrm{r})$ & $\mathrm{u}_{\mathrm{p}}$ & $\mathbf{u}_{\mathrm{k}}$ & $\mathrm{P}(\mathrm{r})$ & $u_{p}$ & $\mathrm{u}_{\mathrm{K}}$ & $\mathrm{s}$ & $\mathrm{r}$ \\
\hline 3 & 2 & 0.8571 & -0.7619 & 0.0476 & 0.9000 & -0.5333 & 0.0333 & 3 & 2 \\
\hline 3 & 3 & 0.1428 & 4.5714 & -0.2857 & 0.1000 & 4.8000 & -0.3000 & 3 & 3 \\
\hline 4 & 2 & 0.7297 & -1.5855 & 0.1096 & 0.8059 & -1.1144 & 0.0779 & 4 & 2 \\
\hline 4 & 3 & 0.2432 & 3.7477 & -0.2792 & 0.1791 & 4. 2189 & -0.3109 & 4 & 3 \\
\hline 4 & 4 & 0.0270 & 9.0810 & -0.4459 & 0.0149 & 9.5522 & -0.4776 & 4 & 4 \\
\hline 5 & 2 & 0.6171 & -2.4685 & 0.1886 & 0.7180 & -1.7446 & 0.1364 & 5 & 2 \\
\hline 5 & 3 & 0.3085 & 2.8647 & -0.2650 & 0.2393 & 3. 5886 & -0.3173 & 5 & 3 \\
\hline 5 & 4 & 0.0685 & 8.1981 & -0.4595 & 0.0398 & 8.9219 & -0.5117 & 5 & 4 \\
\hline 5 & 5 & 0.0057 & 13.5314 & -0.5428 & 0.0026 & 14. 2553 & -0.5950 & 5 & 5 \\
\hline 6 & 2 & 0.5185 & -3.4076 & 0.2876 & 0.6364 & -2.4250 & 0.2117 & 6 & 2 \\
\hline 6 & 3 & 0.3457 & 1.9257 & -0.2416 & 2828 & 2.9083 & -0.3176 & 6 & 3 \\
\hline 6 & 4 & 0.1152 & 7.2590 & -0.4685 & 0.0707 & 8.2416 & -0.5444 & 6 & 4 \\
\hline 6 & 5 & 0.0192 & 12.5924 & -0.5657 & 0.0094 & 13.5750 & -0.6416 & 6 & 5 \\
\hline 6 & 6 & 0.0012 & 17.9257 & -0.6073 & 0.0005 & 18.9083 & -0.6833 & 6 & 6 \\
\hline 7 & 2 & 0.4330 & -4.3987 & 0.4101 & 0.5611 & -3.1557 & 0.3074 & 7 & 2 \\
\hline 7 & 3 & 0.3608 & 0,9345 & -0.2073 & 3117 & 2.1775 & -0.3101 & 7 & 3 \\
\hline 7 & 4 & 0.1603 & 6.2678 & -0.4720 & 0.1039 & 7,5108 & -0.5747 & 7 & 4 \\
\hline 7 & 5 & 0.0401 & 11.6012 & -0.5854 & 0.0207 & 12.8442 & -0.6882 & 7 & 5 \\
\hline 7 & 6 & 0.0053 & 16.9345 & -0.6340 & 0.0023 & 18.1775 & -0.7368 & 7 & 6 \\
\hline 7 & 7 & 0.0003 & 22. 2678 & -0.6549 & 0.0001 & 23.5108 & -0.7576 & 7 & 7 \\
\hline 8 & 2 & 0.3594 & -5.4377 & 0.5599 & 0.4921 & -3.9368 & 0.4275 & 8 & 2 \\
\hline 8 & 3 & 0.3594 & -0.1044 & -0.1 & 80 & 1. & -0.2929 & 8 & 3 \\
\hline 8 & 4 & 0.1996 & 5.2289 & -0.4692 & .1367 & 6.7298 & -0.6016 & 8 & 4 \\
\hline 8 & 5 & 0.0665 & 10.5622 & -0.6016 & .0364 & 12.0631 & -0.7340 & 8 & 5 \\
\hline 8 & 6 & 0.0133 & 15.8955 & -0.6583 & 0.0060 & 17.3965 & -0.7907 & 8 & 6 \\
\hline 8 & 7 & 0.0014 & 21.2289 & $-0,6826$ & .0005 & 22.7298 & -0.8150 & 8 & 7 \\
\hline 8 & 8 & 0.0000 & 26.5622 & -0.6930 & 0.0000 & 28.0631 & -0.8254 & 8 & 8 \\
\hline 9 & 2 & 0.2966 & -6.5200 & 0.7415 & 0.4292 & -4.7674 & 0.5768 & 9 & 2 \\
\hline 9 & 3 & 0.3461 & -1.1866 & -0.0990 & 3338 & 0.5659 & -0.2636 & 9 & 3 \\
\hline 9 & 4 & 0.2307 & 4. 1466 & -0.4592 & 1669 & 5.8992 & -0.6239 & 9 & 4 \\
\hline 9 & 5 & 0.0961 & 9.4799 & -0.6136 & 0.0556 & 11.2325 & -0.7783 & 9 & 5 \\
\hline 9 & 6 & 0.0256 & 14.8133 & -0.6797 & 0.0123 & 16.5659 & -0.8444 & 9 & 6 \\
\hline 9 & 7 & 0.0042 & 20.1466 & -0.7081 & 0.0017 & 21.8992 & -0.8728 & 9 & 7 \\
\hline 9 & 8 & 0.0004 & 25.4799 & -0.7203 & 0.0001 & 27.2325 & -0.8849 & 9 & 8 \\
\hline 9 & 9 & 0.0000 & 30.8133 & -0.7255 & 0.0000 & 32.5659 & -0.8901 & 9 & 9 \\
\hline 10 & 2 & 0.2435 & -7.6408 & 0.9599 & 0.3724 & -5.6463 & 0.7607 & 10 & 2 \\
\hline 10 & 3 & 0.3247 & -2.3074 & -0.0206 & 0.3310 & -0.3129 & -0.2198 & 10 & 3 \\
\hline 10 & 4 & 0.2525 & 3.0258 & -0.4409 & 0.1931 & 5,0203 & -0.6401 & 10 & 4 \\
\hline 10 & 5 & 0.1262 & 8.3591 & -0.6210 & 0.0772 & 10.3536 & -0.8202 & 10 & 5 \\
\hline 10 & 6 & 0.0420 & 13.6925 & -0.6982 & 0.0214 & 15.6870 & -0.8974 & 10 & 6 \\
\hline 10 & 7 & 0.0093 & 19.0258 & -0.7313 & 0.0040 & 21.0203 & -0.9305 & 10 & 7 \\
\hline 10 & 8 & 0.0012 & 24.3591 & -0.7454 & 0.0005 & 26.3536 & -0.9446 & 10 & 8 \\
\hline 10 & 9 & 0.0001 & 29.6925 & -0.7515 & 0.0000 & 31.6870 & -0.9507 & 10 & 9 \\
\hline 10 & 10 & 0.0000 & 35.0258 & -0.7541 & 0.0000 & 37.0203 & -0.9533 & 10 & 10 \\
\hline
\end{tabular}

Note: Omitted the figure below the fifth place of decimals. 
Table A4. Probability and $u$ scores for the hypothesis that $H_{0}: p=1 / 2, k=0$ and $\pi$ in the doubly recessive model. II. Multiplex family alone.

\begin{tabular}{|c|c|c|c|c|c|c|c|c|c|}
\hline \multicolumn{5}{|c|}{ Single ascertainment $(\pi \rightarrow 0)$} & \multicolumn{5}{|c|}{ Truncated ascertainment $(\pi=1)$} \\
\hline $\mathbf{s}$ & $\mathbf{r}$ & $\mathrm{P}(\mathbf{r})$ & $\mathbf{u}_{\mathrm{p}}$ & $\mathrm{u}_{\mathrm{k}}$ & $\mathrm{P}(\mathrm{r})$ & $u_{p}$ & $u_{k}$ & $s$ & $\mathrm{r}$ \\
\hline 3 & 2 & 0.6666 & -1.3333 & 0.0833 & 0.7500 & -1.0000 & 0.0625 & 3 & 2 \\
\hline 3 & 3 & 0.3333 & 2.6666 & -0.1666 & 0.2500 & 3.0000 & -0.1875 & 3 & 3 \\
\hline 4 & 2 & 0.4285 & -2.8571 & 0.2321 & 0.5454 & -2.1818 & 0.1818 & 4 & 2 \\
\hline 4 & 3 & 0.4285 & 1.1428 & -0.1428 & 0.3636 & 1.8181 & -0.1931 & 4 & 3 \\
\hline 4 & 4 & 0.1428 & 5.1428 & -0.2678 & 0.0909 & 5.8181 & -0.3181 & 4 & 4 \\
\hline 5 & 2 & 0.2666 & -4.5333 & 0.4791 & 0.3846 & -3.5384 & 0.3918 & 5 & 2 \\
\hline 5 & 3 & 0.4000 & -0.5333 & -0.0833 & 0.3846 & 0.4615 & -0.1706 & 5 & 3 \\
\hline 5 & 4 & 0.2666 & 3.4666 & -0.2708 & 0.1923 & 4. 4615 & -0.3581 & 5 & 4 \\
\hline 5 & 5 & 0.0666 & 7.4666 & -0.3333 & 0.0384 & 8.4615 & -0.4206 & 5 & 5 \\
\hline 6 & 2 & 0.1612 & -6.3225 & 0.8719 & 0.2631 & -5.0526 & 0.7423 & 6 & 2 \\
\hline 6 & 3 & 0.3225 & -2.3225 & 0.0282 & 0.3508 & -1.0526 & -0.1014 & 6 & 3 \\
\hline 6 & 4 & 0.3225 & 1.6774 & -0.2530 & 0.2631 & 2.9473 & -0.3826 & 6 & 4 \\
\hline 6 & 5 & 0.1616 & 5.6774 & -0.3467 & 0.1052 & 6.9473 & -0.4764 & 6 & 5 \\
\hline 6 & 6 & 0.0322 & 9.6774 & -0.3780 & 0.0175 & 10.9473 & -0.5076 & 6 & 6 \\
\hline 7 & 2 & 0.0952 & -8.1904 & 1.4809 & 0.1250 & -6.7000 & 1. 3063 & 7 & 2 \\
\hline 7 & 3 & 0.2381 & -4.1904 & 0.2152 & 0.2916 & -2.7000 & 0.0407 & 7 & 3 \\
\hline 7 & 4 & 0.3174 & -0.1904 & -0.2066 & 0.2916 & 1.3000 & -0.3811 & 7 & 4 \\
\hline 7 & 5 & 0.2381 & 3.8095 & -0.3472 & 0.1750 & 5.3000 & -0.5217 & 7 & 5 \\
\hline 7 & 6 & 0.0952 & 7.8095 & -0.3941 & 0.0583 & 9.3000 & -0.5686 & 7 & 6 \\
\hline 7 & 7 & 0.0158 & 11.8095 & -0.4097 & 0.0083 & 13.3000 & -0.5842 & 7 & 7 \\
\hline 8 & 2 & 0.0551 & -10.1102 & 2.41 & 0.1133 & -8.4534 & 2. 1916 & 8 & 2 \\
\hline 8 & 3 & 0.1653 & -6.1102 & 0.5125 & 0.2267 & -4.4534 & 0.2932 & 8 & 3 \\
\hline 8 & 4 & 0.2755 & -2.1102 & -0.1202 & 0.2834 & -0.4534 & -0.3395 & 8 & 4 \\
\hline 8 & 5 & 0.2755 & 1.8897 & -0.3312 & 0.2267 & 3.5465 & -0.5505 & 8 & 5 \\
\hline 8 & 6 & 0.1653 & 5.8897 & -0.4015 & 0.1133 & 7.5465 & -0.6208 & 8 & 6 \\
\hline 8 & 7 & 0.0551 & 9.8897 & -0.4249 & 0.0323 & 11.5465 & -0.6442 & 8 & 7 \\
\hline 8 & 8 & 0.0078 & 13.8897 & -0.4327 & 0.0040 & 15.5465 & -0.6520 & 8 & 8 \\
\hline 9 & 2 & 0.0313 & -12.0627 & 3. 8197 & 0.0717 & -10.2868 & 3. 5578 & 9 & 2 \\
\hline 9 & 3 & 0.1098 & -8.0627 & 0.9721 & 0.1673 & -6.2868 & 0.7102 & 9 & 3 \\
\hline 9 & 4 & 0.2196 & -4.0627 & 0.0229 & 0.2510 & -2.2868 & -0.2386 & 9 & 4 \\
\hline 9 & 5 & 0.2745 & -0.0627 & -0.2935 & 0.2510 & 1.7131 & -0.5554 & 9 & 5 \\
\hline 9 & 6 & 0.2196 & 3.9372 & -0.3989 & 0.1673 & 5.7131 & -0.6608 & 9 & 6 \\
\hline 9 & 7 & 0.1098 & 7.9372 & -0.4341 & 0.0717 & 9.7131 & -0.6960 & 9 & 7 \\
\hline 9 & 8 & 0.0313 & 11.9372 & -0.4458 & 0.0179 & 13.7131 & -0.7077 & 9 & 8 \\
\hline 9 & 9 & 0.0039 & 15.9372 & -0.4497 & 0.0019 & 17.7131 & -0.7116 & 9 & 9 \\
\hline 10 & 2 & 0.0176 & $-14,0352$ & 5.9438 & 0.0444 & -12.1776 & 5.6430 & 10 & 2 \\
\hline 10 & 3 & 0.0704 & -10.0352 & 1.6723 & 0.1184 & -8.1776 & 1.3715 & 10 & 3 \\
\hline 10 & 4 & 0.1643 & -6.0352 & 0.2485 & 0.2073 & -4.1776 & -0.0522 & 10 & 4 \\
\hline 10 & 5 & 0.2465 & -2.0352 & -0.2260 & 0.2487 & -0.1776 & -0.5268 & 10 & 5 \\
\hline 10 & 6 & 0.2465 & 1.9647 & -0.3842 & 0.2073 & 3.8223 & -0.6850 & 10 & 6 \\
\hline 10 & 7 & 0.1643 & 5.9647 & -0.4370 & 0.1184 & 7.8223 & -0.7378 & 10 & 7 \\
\hline 10 & 8 & 0.0704 & 9.9647 & -0.4545 & 0.0444 & 11.8223 & -0.7553 & 10 & 8 \\
\hline 10 & 9 & 0.0176 & 13.9647 & -0.4604 & 0.0098 & 15.8223 & -0.7612 & 10 & 9 \\
\hline 10 & 10 & 0.0019 & 17.9647 & -0.4623 & 0.0009 & 19.8223 & -0.7632 & 10 & 10 \\
\hline
\end{tabular}

Note: Omitted the figure below the fifth place of decimals. 
Acknowledgements We are indebted to Mr. Kenjiro Fukuhisa for his technical assistance in running computer programs on ACOS-700S installed in the National Institute of Radiological Sciences.

This study was supported in part by a grant for the Intractable Diseases from Ministry of Health and Welfare of Japan. Aided also in part by the Grant-in-aid for Scientific Research no. 58570980 from Ministry of Education, Science and Culture of Japan.

\section{REFERENCES}

Barrai, I., Mi, M.P., Morton, N.E., and Yasuda, N. 1965. Estimation of prevalence under incomplete selection. Am. J. Hum. Genet. 17: 221-236.

Defrise-Gussenhoven, E. 1962. Hypotheses de dimerie et de non-penetrance. Acta Genet. (Basel) 12: $65-96$.

Elandt-Johnson, R.C. 1970. Segregation analysis for complex modes of inheritance. Am. J. Hum. Genet. 22: 129-194.

Elston, N.C. and Namboodini, K.K. 1977. Cited in Elston, R.C. 1981. Segregation analysis. In Advances in Human Genetics, Harris, H. and Hirschhorn, K., eds., Plenum, New York, pp. 63-373.

Greenberg, D.A. 1984. Simulation studies of segregation analysis: application to two-locus models. Am. J. Hum. Genet, 36: 167-176.

Greenberg, D.A. and Anderson, C.E. 1983. The search for heterogeneity in insulin dependent diabetes mellitus: evidence for familial and nonfamilial forms. Am. J. Med. Genet. 14: 487499.

Greenberg, D.A., Hodge, S.E., and Rotter, I.J. 1982. Evidence for recessive and against dominant inheritance at the HLA-linked locus in coeliac disease. Am. J. Hum. Genet. 34: 263-277.

Greenberg, D.A. and Lange, K.L. 1982. A maximum likelihood test of the two-locus model for coeliac disease. Am. J. Med. Genet. 12: 75-82.

Greenberg, D.A. and Rotter, J.I. 1981. Two locus models for gluten sensitive enteropathy: population genetic considerations. Am. J. Med. Genet. 8: 205-214.

Haldane, J.B.S. 1949. A test for homogeneity of records of familial abnormalities. Ann. Eugen. 14: $339-341$.

Hartl, D.L. and Maruyama, T. 1968. Phenogram enumeration: number of regular genotypephenotype correspondences in genetic systems. J. Theor. Biol. 20: 129-163.

Hogben, L. 1932. The genetic analysis of familial traits. II. Double gene substitutions, with special reference to hereditary dwarfism. J. Genet. 25: 211-240.

Kagnoff, M.F. 1982. Two genetic loci control the murine immune response to A-gliadin, a wheat protein that activates coeliac sprue. Nature 296: 158-160.

Lalouel, J.M. and Morton,N.E. 1981. Complex segregation analysis with pointers. Hum. Hered. 31: $312-321$.

Li, C.C. 1953. Some general properties of recessive inheritance. Am. J. Hum. Genet. 5: 269-279.

Morton, N.E. 1959. Genetic tests under incomplete ascertainment. Am. J. Hum. Genet. 11: 1-16.

Morton, N.E. 1969. Segregation analysis. In Computer Application in Genetics, Morton, N.E., ed., The Univ. Hawaii Press, Honolulu, pp. 129-139.

Nakao, Y., Matsumoto, H., Miyazaki, T., Mizuno, N., Arima, N., Wakisaka, A., Okimoto, K., Akazawa, Y., Tsuji, K., and Fujita, T. 1981. IgG heavy-chain (Gm) allotypes and immune response to insulin in insulin-requiring diabetes mellitus. New Eng. J. Med. 304: 407-409.

Sasazuki, T., Uno, H., Yasuda, N., Tamai, H., and Matsumoto, H. 1982. Evidence for HLA-linked and Gm-linked genes in Graves disease. Proc. Clin. \& Biol. Res., B, Bone-Tamin, ed., Alan R. Liss, Inc., New York, 103B, pp. 65-76. 
Thomson, G. 1980. A two-locus model for juvenile diabetes. Ann. Hum. Genet. 43: 385-398. Uno, H., Sasazuki, T., Tamai, H., and Matsumoto, H. 1981. Two major genes linked to HLA and $\mathrm{Gm}$ control susceptibility to Graves disease. Nature 292: 268-270.

Utermann, G., Langenbeck, U., Beisiegel, U., and Weber, W. 1980. Genetics of apolipoprotein E-system in man. Am. J. Hum. Genet. 32: 339-347.

Yasuda, N. 1982. A note on segregation analysis of multiplex family. Jpn. J. Hum. Genet. 27: $1-8$.

Yasuda, N. and Sasazuki, T. 1982. Affected sib pair method for searching major gene in multifactorial disease. Jpn. J. Human Genet. 27: 295-311. 